\title{
DESCRIÇÃO DAS MANIFESTAÇÕES DE CORPORTAMENTO APRESENTADAS POR PACIENTES COM DIAGNÓSTICO DE ESQUISOFRENIA
}

Maguida Costa Stefanelli*

Dra. Evalda Cançado Arantes*

\begin{tabular}{l|l|}
\cline { 2 - 2 } & $\mathrm{RBEn} / 04$ \\
\hline
\end{tabular}

STEFANELLI, M.C. \& ARANTES, E.C. - Descrição das manifestações de comportamento apresentadas por pacientes c/ diagróstico de Esquisofrenia. Rev. Bras. Enf.; RJ, 28 : 9-21, 1975.

\section{INTRODUÇÃO}

Observa-se, quando no ensino de Enfermagem Psiquiátrica, que uma das maiores dificuldades do pessoal do hospital e dos estudantes de enfermagem é fazer relatos, descritivos e completos, das maneiras pelas quais os pacientes se comportam.

Os relatos apresentados nos diferentes turnos de serviço sugerem, para uma mesma manifestação de comportamento, idéias diversas. Essa diversidade torna difícil não só a elucidação do diagnóstico e a indicação do tratamento do paciente, como também a elaboração do plano de assistência de enfermagem. uma vez que cada membro da equipe terapêutica pode interpretar de modo diverso o que está registrado sobre o comportamento do doente.

O problema fica mais evidente ainda nos casos de esquizofrenia, pois as manifestações dessa perturbação mental são muito complicadas para descrever, em decorrência das peculiaridades de suas manifestações.

As falhas nos relatos de observações devem ser causadas por deficiências no ensino de Enfermagem Psiquiátrica, tanto nas escolas como nos hospitais. Além disso, é de supor-se que também a escasez de literatura específica, em língua portuguesa, tenha sua parcela de responsabi'idade no caso. $\mathrm{Na}$ literatura rorte-americana é onde se encontra o maior número de estudos de enfermagem a respeito do comportamento de doentes mentais; mas não há, nesses trabalhos, a preocupação de descrição minuciosa e completa de um determinado tipo de comportamento.

O "Levantamento de recursos e necessidades de enfermagem no Brasil", realizado em 1957, mostrou que, naquela época, $33,3 \%$ das escolas de enfermagem não ofereciam. a seus alunos, estágio em clínica psiquiátrica. O curso de enfer-

* Docentes de Enfemagem Psiquiátrica, na Escola de Enfermagem da Universidade de São Paulo. 
STEFANELLI, M.C. \& ARANTES, E.C. - Descrição das manifestações de comportamento apresentadas por pacientes c/ diagnóstico de Esquisofrenia. Rev. Bras. Enf.; RJ, 28 : $9-21,1975$.

magem sofreu modificações; contudo, não se conta com dados precisos de como e quanto o ensino de Enfermagem Psiquiátrica evoluiu, desde então.

Numa tentativa de colaboração para sanar, em parte, essas imperfeições, elaborou-se a presente pesquisa, que partiu da pergunta: A introdução de um roteiro, que contivese elementos descritivos das manifestações de comportamento apresentadas por pacientes esquizofrênicos, tornaria o relato clescritivo e completo?

Foram nossos objetivos: analisar as observações do comportamento de pacientes esquizofrênicos, feitas por alunos e docentes de Enfermagern Psiquiátrica; elaborar um roteiro para observação de comportamento de pacientes com o referido diagnóstico e avaliar a validade desse roteiro.

\section{REVISÃO DE LITERATURA}

Apenas dois trabalhos nacionais sobre descrição de comportamento temos a destacar:

ARANTES (1968) apresenta um roteiro para observação de comportamento de pacientes internados em hospital psiquiátrico, que fornece elementos para uma observação completa; não é, porém, específico para pacientes com sintomas de esquizofrenia.

ARANTES (1972), em sua tese de doutoramento apresentada à Escola de Enfermagem da Universidade de São Paulo, citou, como um dos objetivos propostos, este: verificar se uma "checklist", em que houvesse elementos descritivos de comportamento, aumentaria quantitativamente os aspectos de comportamento relatados pelos atendentes de hospitais psiquiátricos. Concluiu que, nas anotações feitas por esses atendentes, houve enriquecimento considerável na observação, quando feita com o uso da "check-list".

Da literatura americana podem ser citados:
MERENESS \& KARNOSH (1964), MANFREDA (1968), MATHENEY \& TOPALIS (1971), BURGESS \& LAZARE (1973) descrevem algumas manifestações de sintomas de esquizofrenia.

TRAVELBEE (1969) salienta a importância de a enfermeira relatar o que vê e o que ouve, sem interpretações de sua parte. Quando o comportamento é de difícil compreensão, como no caso de pacientes esquizofrênicos, isso se torna ainda mais importante.

HOELING et al. (1970) afirmam que a enfermeira identifica as necessidades do paciente, baseando-se nas observações que faz a respeito do comportamento dele.

TUDOR (1970) faz o relato de uma observação profunda e contínua, realizada durante seis meses, do comportamento de dois pacientes esquizofrênicos crônicos. Baseada nessa observação, fez uma análise da assistência de enfermagem. A publicação dessa análise provocou reação, para mudança de conduta profissional, no grupo de enfermeiras psiquiátricas norte-americanas.

\section{METODOLOGIA}

\section{População}

O estudo foi realizado com docentes de Enfermagem Psiquiátrica e alunos do curso de Graduação em Enfermagem, que observaram pacientes, com diagnóstico de esquizofrenia, internados no hospital psiquiátrico, que oferece campo de prática à Escola, e com idade superior a 13 anos.

\section{Técnica}

1. Levantamento de descrições de comportamento de pacientes esquizofrênicos, feitas por docentes de Enfermagem Psiquiátrica.

2. Levantamento de descrições de comportamento de pacientes esquizofrênicos. realizados por alunos do terceiro ano do Curso de Graduação em Enfermagem. 
STEFANELLI, M.C. \& ARANTES, E.C. - Descrição das manifestações de comportamento apresentadas por pacientes c/ diagnóstico de Esquisofrenia. Rev. Bras. Enf.; RJ, 28 : 9-21, 1975.

3. Elaboração de um roteiro com elementos descritivos do comportamento apresentado pelos pacientes observados por docentes e alunos (Anexo II).

A - Utilização do roteiro (Anexo I), como base para descrições de comportamento, por parte dos alunos de Enfermagem, ao relatarem as observações de comportamento de pacientes esquizofrênicos. Nesta parte do estudo, foi aconselhada a seguinte conduta para o período de observação:

a. Abster-se de procurar qualquer informação sobre o paciente, não colhida das próprias observações: não ler os prontuários dos pacientes e as fichas do "Kardex"; não conversar sobre os doentes com os funcionários da clínica; não ler nada sobre o diagnóstico do paciente ou sua psicopatologia, nos dias de observação (primeira semana do curso e do estágio).

b. Fazer observação sistematizada nāo participante, no primeiro dia, e observação sistematizada participante, nos três dias posteriores.

c. Anotar todas as observações realizadas, com pormenores, para facilitar o relato escrito e evitar omissão de elementos importantes.

d. Fazer relatos, descritivos e sem qualquer interpretação, das modalidades de comportamento observados, seguindo uma re!ação de elementos gerais considerados importantes na descrição de comportamento (Anexo I).

Nessa fase de observação, evitou-se, durante as aulas, fazer qualquer comentário a respeito de psicopatologia; além disso, as orientações e aulas dadas versaram apenas sobre conhecimentos básicos da Enfermagem Psiquiátrica em geral.

5. Relato escrito das observações efetuadas: foi realizado em sala de aula, após o quario dia de observação, e desta forma:

$1 .{ }^{\circ}$ relato - descrição das modalidades de comportamento observadas nos pacientes esquizofrênicos, com o uso da relação de elementos para observar (Anexo I), dada inicialmente, e as anotações feitas durante os quatro dias de observa,ção.

$2 .^{\circ}$ relato - nova descrição das modalidades de comportamento observadas nos pacientes esquizofrênicos, realizada no dia seguinte e sem novo contato com os doentes. Neste segundo relato, foi apresentado aos estudantes um "roteiro" (Anexo II) e pediu-se lhes que o lessem e nele assinalassem os ítens que descreviam as modalidades de comportamento apresentadas pelos seus pacientes. Após a leitura e a assinalação do roteiro, foi elaborada a nova descrição, utilizandose também o material que servirá ao relato anterior.

\section{RESULTADOS E COMENTÁRIOS}

A pesquisa foi realizada durante 0 ano letivo de 1974, com 50 alunos que observaram, sistematicamente e pela primeira vez, pacientes esquizofrênicos. Não foram consideradas as observações dos repetentes, que pela segunda ou terceira vez cursavam a disciplina; da mesma forma, os estudantes que observaram pacientes com outro tipo de diagnóstico não participaram.

O roteiro especial para observação de pacientes esquizofrênicos (Anexo II) foi elaborado, após seleção de elementos descritivos de comportamento contidos nas observações feitas pelas quatro docentes da disciplina Enfermagem Psiquiátrica, de 1970 a 1973 , e por 35 alunos do terceiro ano do Curso de Graduação em Enfermagem, que estudaram a disciplina em 1973. As observações de comportamento, efetuados por esses docentes e cstudantes, foram feitas com a utilização do "Roteiro para observação do paciente" (1), que contém os elementos gerais a serem observados no comportamento dos doentes, quando internados, 
STEFANELLI, M.C. \& ARANTES, E.C. - Descrição das manifestações de comportamento apresentadas por pacientes c/ diagnóstico de Esquisofienia. Rev. Bras. Enf.; RJ, 28 : 9-21, 1975.

para que o relato das observações seja completo.

O roteiro contém 206 ítens para assinalar. O resultado da contagem do número de vezes em que cada item foi assinalado está contido no Anexo II (dados acrescentados, depois de findo o estudo). Os resultados, agrupados segundo os títulos do roteiro, estão expressos no Quadro 1 .

Como ficou evidente, os itens, contidos nos títulos, receberam em média 9,31 assinalações, numa amp.itude de médias de 1,75 a 14,88 .

No título "visitantes", em que se procura descrever as reações do paciente no encontro com seus familiares, obteve-se a menor média $(1,75)$, o que pode ser justificado pelas condições em que se realizou o estudo. Os estudantes:

a. foram aconselhados a escolher, de preferência, pacientes recém-admitidos e estes ficaram. em geral, sem receber visitas nos primeiros 15 dias após a interração, conforme a rotina do hospital onde o estudo foi feito;

b. foram proibidos de ler as anotações sobre o paciente e, mesmo. de conversar com o pessoal do hospital sobre as suas observações;

c. fizeram as observações de comportamento na primeira semana de estágio, sem qualquer conhecimento formal de psicopatologia e em um só horário - o da manhã - sendo que os pacientes recebem visitas aos sábados e domingos, à tarde.

Quadro 1 - Número e média de itens assinalados e deixados em branco, no roteiro, por 50 estudantes do curso dé Graduação em Enfermagem (1974).

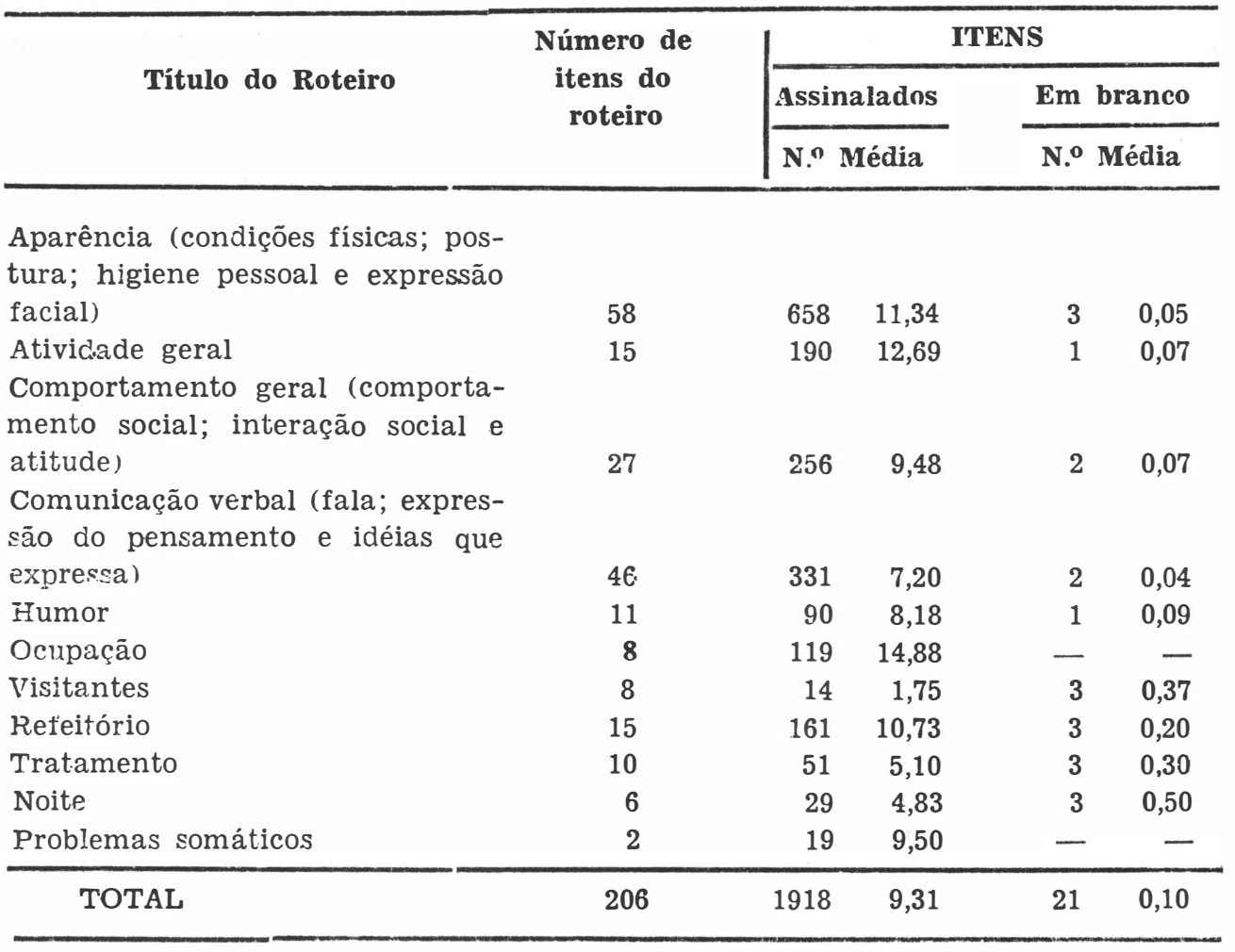


STEFANELLI, M.C. \& ARANTES, F.C. - Descrição das manifestações de comportamento apresentadas por pacientes c/ diagnóstico de Esquisofrenia. Rev. Bras. Enf.; RJ, 28 : $9-21,1975$.

O tópico "noite", com a segunda menor média de assinalação $(4,83)$, poderia também receber as mesmas considerações precedentes, quanto ao horário de estágio.

Quanto a "ccupação" - que procura estimular a descrição de atividades produtivas dos pacientes - e "atividade geral", tôm suas médias de assinalação (14,88 e 12,67) justificadas pelas próprias características dos doentes observados.

Dos 206 ítens do roteiro. 21 não foram assinalados uma só vez. Estes merecem uma análise posterior, pois, ou não estão suficientemente claros, ou os estudantes não tiveram oportunidade de analisar os comportamentos descritos, durante o período de observação. Devem, entretanto, ser mantidos após reformulação, porque, como pode ver-se na relação abaixo, correspondem a manifestações de psicopatologia, de formas clínicas da esquizofrenia, encontradas nas observações anteriores que serviram de base para 0 roteiro específico.

Relação de ítens não assinalados:

\section{APARÊNCIA}

Higiene pessoal:

- precisa ser lembrado, para urinar e evacuar.

Expressão facial:

- quando anda, olha sempre para trás.

- às vezes, fica olhando muito tempo para determinada parte de seu corpo, parecendo estranhar o próprio corpo.

2. ATIVIDADE GERAL

- anda com as mãos fechadas, batendo-as nas paredes.

\section{COMPORTAMENTO GERAL}

Comportamento social:

- não vai a culto religioso.

- não vai aos "shows" e às sessões de cinema.
4. COMUNICAÇÃO VERBAL

Idéias que expressa:

- diz que querem matá-lo.

- diz que ele não existe.

5. HUMOR

- Chora, ao ouvir falar de coisas alegres.

\section{VISITANTES}

- recusa-se a recebê-los.

- grita com os visitantes.

- só recebe os visitantes, se é levado até eles.

\section{REFEITÓRIO}

- recusa toda alimentação.

- diz estar vendo bichos na comida.

- diz não comer, porque é santo.

8. TRATAMENTO

- não aceita tratamento.

-_ não toma medicação, dizendo que é veneno.

- não aceita medicação, com medo de ficar "impregnado".

\section{NOITE}

- queixa-se de que tem sono agitado.

-- diz haver sonhado sempre com a mesma coisa.

- diz que não quer dormir porque sonha com "coisa ruim".

No final da relação de íten $S$ correspondentes a cada título geral, há o tópico "outras observações", que aparece 17 vezes no roteiro. Ele foi assinalado 287 vezes, com média de assinalação igual a 16,88 . maior, portanto, do que a média geral de assinalações. Ora, com a enumeração dos ítens contidos no Anexo II, não se pretendeu fazer uma descrição completa de todos os tipos de comportamento, mas, sim, oferecer estímulos, para que a observação feita pelo estudante fosse a mais completa possível, dar, a ele, elementos, para tornar descritivo seu relato de observação e, ao 
STEFANELLI, M.C. \& ARANTES, E.C. - Descrição das manifestações de comportamento apresentadas por pacientes c/ diagnóstico de Esquisofrenia. Rev. Bras. Enf.; RJ, 28 : $9-2$

mesmo tempo, ajudá-lo a localizar as características do comportamento observado, quando não soubesse colocá-las dentro do todo. Nessas condições, o ítem "outras observações" deve ser mantido, mesmo que se tente deixar o roteiro o mais completo possível. Com ele, serão evitadas observações de comportamento estereotipadas e haverá oportunidade de respeito à forma peculiar com que o paciente exibe os seus sintomas.

\section{CONCLUSÃO}

Com os dados do estudo, podemos concluir que o roteiro especial é eficaz para a observação de doentes esquizofrênicos.
Os 50 alunos que participaram da pesquisa assinalaram, em média, 38,36 dos seus ítens (206), o que equivale a dizer que usaram, em média, $18,6 \%$ do roteiro como estímulo para descrição das manifestações de comportamento por eles obscrvadas.

\section{RECOMENDAÇÃO}

As autoras recomendam que sempre seja usado um roteiro, na observação de paciente esquizofrênico, para que o relato da mesma fique completo.

Recomendam, também, que se tente fazer uma análise qualitativa de observações realizadas com e sem um roteiro especial, para torná-lo menos extenso.

\section{REFERENCIAS BIBLIOGRA FICAS}

ASSOCIAÇÃO BRASTLEIRA DE ENFERMAGEM - Levantamento dos recursos e necessidades de enfermogem. Rio de Janeiro, AREn, 1959 (mimeografado).

Burgess, A. C. \& LAzare, A - Psychiatric nursing in the hospital and the community. Englewood Clirs, Prentice-Hall, 1973.

HOFLING, C. K. et al. - Enfermería psiquiátrica. 2 ed. México, Interamericana, p. 1. 262-96, 1970.

MANFREDA, M. L. - Psychiatric nursing. 8 ed. Philadelphia, Davis, p. 311-27, 1968.
MATHENEY, R. V. \& TOPALIS, M. - Enfermería psiquiátrica. 5 ed. México, Interamericana, p. 131-44, 1962.

MERENESS, D. \& KARNOSH, L. J. Elementos de enfermería psiquiátrica. México, Frensa Médica, p. 172-85, 1964.

TRAVELBEE, J. - Intervention in psychiatric nursing: process in the onetione relationship. Philadelphia, Davis, p. 29-31, 1969.

TUDOR, Gwen E. - A sociopsychiatric nursing approach to intervention in a problem of mutual withdrawal on a mental hospital ward. Perpectives in Psychiatric Care, 8 (1): 11-35, 1970. 
1. APARENCIA

— condições físicas;

- postura;

- expressão facial;

- higiene pessoal.

\section{ATIVIDADE GERAL}

3. COMPORTAMENTO GERAL

- comportamento social;

— interação social;

- atitude.

4. COMUNICAÇÃO VERBAL

- fala;

- expressão de pensamento;
- idéia que expressa.

5. HUMOR

\section{PROBLEMAS SOMATICOS}

- queixas do paciente;

- observação.

7. COMPORTAMENTO EM SITUAÇÕES ESPECIAIS

- unidade;

- terapia ocupacional;

- acontecimentos sociais;

- visitantes;

- tratamento;

- refeitório;

- noite.

\section{ANEXO II}

Roteiro para observação de paciente.

Identificação do paciente:

Nome:

Sexo:

Idade (anos): ........

Estado civil: .......... Nacionalidade: .......... Relígião

Procedência : ............... Residência:

(Cidade.)

(Estado.)

Profissão ou ocupação:

Data de Admissão:

N. ${ }^{\circ}$ de Registro:

Com um " $x$ " colocado no traço que precede a palavra ou a frase, assinale as descrições que mais se aproximam do comportamento apresentado pelo paciente que se observou.

N. de $^{\circ}$ vezes

em que foi

assinalado. (1)

1. Aparência:

1.1. Condições físicas:

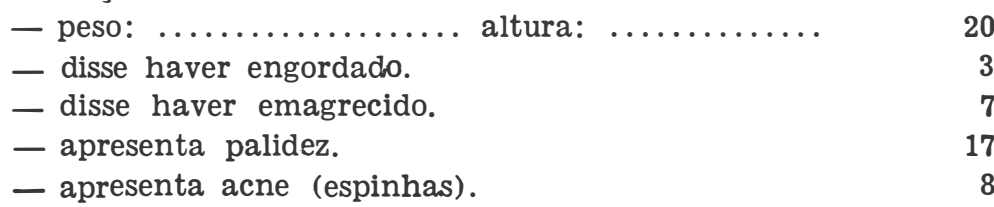

(1) Esta coluna foi acrescentada ao roteiro, para economizar o espaço de outra tabela. 
- apresenta pele gordurosa. $\quad 7$

- apresenta dentes em más condições de higiene. $\quad 17$

- parece envelhecido para sua idade. 5

$\begin{array}{ll}\text { - outras observações. } & 27\end{array}$

1.2. Postura:

- aparenta cansaço. 16

- fica cabisbaixo. 14

- fica curvado. 19

- permanece muito tempo na mesma posição. 22

- fica em posições estranhas. 3

- permanece muito tempo no mesmo lugar. 17

- apresenta-se com braços caídos ao longo do corpo. $\quad 21$

$\begin{array}{ll}\text { - outras observações. } & 20\end{array}$

1.3. Higiene pessoal:

- cuida de sua higiene. 38

— não cuida de sua higiene. $\quad 5$

- precisa ser lembrado, para tomar banho. $\quad 7$

- recusa-se a fazer sua higiene. 2

- precisa ser lembrado para escovar os dentes 9

- tem que ser levado ao banheiro para fazer sua higiene.

- entra com as vestes no chuveiro. 2

- permanece embaixo d'água, sem iniciar o banho. 5

- só toma banho, quando alguém lhe vai dizendo o que fazer. $\quad 6$

— só sai do chuveiro, se alguém o tira de lá 4

- suja as vestes com fezes e urina. 2

- urina, em qualquer lugar. $\quad 2$

- precisa ser lembrado, para urinar e evacuar -

- apresenta unhas sujas. 2

- tem as unhas compridas. $\quad 16$

- seus cabelos parecem sujos ou engordurados. $\quad 6$

- apresenta-se com cabelos despenteados. $\quad 10$

- usa roupas em desalinho (desabotoadas, caindo $\begin{array}{ll}\text { etc.) } & 16\end{array}$

- usa roupas de cores berrantes. 2

- está aparentemente sujo. 2

— está aparentemente limpo. $\quad 40$

— está vestido adequadamente. $\quad 30$

— anda descalço. $\quad 4$

- veste-se de forma inadequada para a temperatu$\begin{array}{ll}\text { ra ambiente. } & 10\end{array}$

— outras observações. 13 
1.4. Expressão facial:

- mímica inexpressiva.

- denota medo de alguém ou alguma coisa.

- olha as pessoas de soslaio.

- não encara as pessoas quando conversa.

- olha fixamente as pessoas quando conversa. 20

- denota tristeza. $\quad 19$

— denota cansaço. $\quad 14$

- parece estar sempre, sorrindo. $\quad 8$

— olha demoradamente para um determinado ponto. $\quad 17$

- aparenta não perceber o que se passa à sua volta. $\quad 24$

- olha rapidamente para as pessoas e desvia o olhar. $\quad 9$

- quando anda, olha sempre para trás.

- quando o chamamos pelo nome, olha-nos como se não nos estivesse vendo.

- às vezes, fica olhando muito tempo para determinadas partes de seu corpo, parecendo estranhar o próprio corpo.

- olha-se no espelho, passando a mão demoradamente pelo rosto.

- outras observações.

2. Atividade geral:

- executa qualquer atividade.

10

- não se ocupa com qualquer atividade.

20

- precisa ser solicitado para participar das atividades da unidade.

- permanece num canto, quieto.

- quando anda, faz movimentos desnecessários com as pernas.

- repete sempre os mesmos movimentos com as mãos. $\quad 6$

- inclina sempre o corpo para o mesmo lado 3

- passa sempre as mãos pelo cabelo. 5

- fica andando pelo corredor a maior parte do tempo. $\quad 25$

- anda lentamente. 21

- corre pelos corredores. 2

— quando anda, só o faz em linha reta. 14

- anda com as mãos fechadas, batendo-as na parede. -

— anda o tempo todo. 10

— outras observações. 21

3. Comportamento geral:

3.1. Comportamento social:

- fica a maior parte do tempo sozinho. 40

— parece não perceber o gue se passa à sua volta. 19

- quando em grupo, parece ignorar as pessoas. 22

- fica junto ao grupo de pacientes, somente quando alguém lá o coloca. 
- executa somente atividades individuais.

- não vai a culto religioso.

- não assiste a programas de televisão.

- não vai aos "shows" e às sessões de cinema.

— outras observações.

3.2. Interação social:

- procura sempre companhia de um determinado paciente.

- quando encontra alguém, procura tocá-lo com as mãos.

- mostra-se excessivamente reservado e formal com as pessoas.

- evita as pessoas do sexo oposto.

- demonstra não querer ficar perto de determinada pessoa.

- despe-se em qualquer lugar.

- masturba-se em qualquer lugar.

- exibe os seus órgãos genitais.

- outras observações.

3.3. Atitude:

- não faz o que lhe é sugerido.

- faz exatamente o contrário do que lhe é sugerido.

- sente-se diferente dos outros.

- diante de uma situação de escolha, não decide o que fazer.

- negligencia suas responsabilidades.

- sente-se inadequado.

- não coopera; está sempre argumentandio.

- está sempre reivindicando alguma coisa.

- outras observações.

4. Comunicação verbal:

4.1. Fala:

- não fala.

- fala vagarosamente.

- fala sem mostrar inflexão na voz.

- murmura as palavras.

- fala em tom de voz muito baixo.

- movimenta os lábios sem, porém, emitir qualquer som.

- fala em tom de voz alto.

- grita, às vezes.

- apresenta peculiaridades no modo de falar.

- outras observações. 
4.2. Expressão do pensamento:

- expressa-se com lógica.

- diz que não consegue expressar o que sente.

- não conclui as frases que inicia.

2

- insiste sempre no mesmo assunto.

- responde com monossílabos.

- fala um amontoado de palavras sem sentido.

- quando perguntamos sobre algum assunto, dá respostas que não estão relacionadas com o mesmo.

- não consegue manter conversação.

- usa palavras estranhas.

- não se entende o conteúdo de sua conversação.

- repete sempre a mesma frase.

- repete várias vezes a mesma palavra, no meio da conversação.

- repete os últimos sons ouvidos.

4.3. Idéias que expressa:

- fala sempre que alguém o persegue. 2

- fala sempre em religião. 3

- diz ser enviado de Deus. 3

- diz ser o salvador do mundo. 2

- diz que querem matá-lo.

- julga ter poderes sobrenaturais.

- acha que forças estranhas controlam sua existência.

- diz não ser ele mesmo.

— diz que ele não existe.

- queixa-se de que tudo é diferente.

- afirma que o mundo está mudado.

- pede sempre, que o deixem ir embora

- afirma não estar doente.

- não expressa seus sentimentos.

- afirma estar vendo algo aue nós não vemos.

- diz ouvir vozes estranhas.

- diz ouvir ruídos.

- diz ter um esgotamento nervoso.

- diz que ninguém é capaz de entendê-lo.

- faz planos para o futuro que estão fora da realidade.

- outras observações.

5. Humor:

- aparenta serenidade.

- parece estar sonhando acordado. 
- passa do choro ao riso, facilmente.

- ri ao falar ou ouvir falar de coisas tristes.

- chora ao ouvir falar de coisas alegres.

- denota tristeza.

- parece não se interessar por nada.

- ri ou chora, aparentemente sem motivo.

- ora denota tristeza, ora alegria.

- grita ou xinga, quando interpelado.

- outras observações.

6. Ocupação:

- não se ocupa com qualquer atividade.

- não termina o que inicia.

- não demonstra interesse em aprender coisas novas.

- fica pouco tempo numa mesma atividade.

- recusa-se a fazer qualquer atividade.

- quando executa alguma atividade, permanece o tempo todo na mesma posição.

- quando alguém o interrompe, não volta à ocupação anterior.

- outras observações.

7. Visitantes:

- parece não tomar conhecimento dos visitantes.

- recusa-se a recebê-los.

- fica junto dos visitantes, mas não conversa.

- grita com os visitantes.

- denota tristeza, quando os visitantes vão embora.

- ignora a saída cos visitantes.

- só recebe os visitantes se é levado até eles.

- outras observações.

3. Refeitório:

- demonstra maneiras adequadas à mesa. 32

— aceita toda alimentação. $\quad 39$

- recusa toda alimentação.

— come vagarosamente. 20

— só se alimenta se alguém diz que o faça. 2

- só se alimenta quando alguém comanda seus movimentos.

— senta-se sempre sozinho à mesa. 18

- procura sentar-se, sempre, no mesmo lugar. $\quad 18$

- recusa determinados alimentos. $\quad 6$

- diz estar vendo bichos na comida.

- diz não ccmer porque é santo.

- come com as mãos. 
- suja-se, ao alimentar-se.

6

- alega algum motivo para recusar a alimentação.

3

- outras observações.

9. Tratamento:

- não aceita tratamento.

- sabe o nome dos remédios que está tomando.

- recusa-se a tomar medicação.

- não toma medicação dizendo que é veneno.

- tem medo de ficar "impregnado".

- não sabe que tratamento está fazendo.

- não aceita medicação com medo de ficar "impregnado".

- não sabe informar que tratamento está fazend.o.

- não sabe dizer se está fazendo tratamento.

- outras observações.

10. Noite:

- queixa-se de que não dorme.

- só dorme, após tomar medicação.

- queixa-se de que tem sono agitado.

- diz haver sonhado sempre com a mesma coisa.

- diz que não quer dormir porque sonha com "coisa ruim".

- outras observações.

11. Problemas somáticos:

- queixas.

— observações. 